\title{
Gestational Trophoblastic Tumor pT2 TNM Finding v7
}

National Cancer Institute

\section{Source}

National Cancer Institute. Gestational Trophoblastic Tumor pT2 TNM Finding v7. NCI

Thesaurus. Code C89699.

Gestational trophoblastic tumor extending to other genital structures (ovary, tube, vagina, broad ligaments) by metastasis or direct extension. (from AJCC 7th Ed.) 